\title{
The Evaluation of the Short-Term Voice Outcome of Injection Laryngoplasty Using Two Types of Calcium Hydroxylapatite (Radiesse versus Facetem)
}

\author{
Hyun Ho Lee, Sung Joon Park ${ }^{\mathbb{D}}$, and Young Hak Park \\ Department of Otorhinolaryngology-Head and Neck Surgery, Yeouido St. Mary's Hospital, College of Medicine, \\ The Catholic University of Korea, Seoul, Korea
}

\section{두 가지 Calcium Hydroxylapatite(Radiesse versus Facetem)를 이용한 Injection Laryngoplasty의 단기 음성 결과의 비교연구}

이현호 · 박성준 · 박영학

가톨릭대학교 의과대학 여의도성모병원 이비인후-두경부외과학교실

\author{
Received February 21, 2019 \\ Revised May 13, 2019 \\ Accepted May 15, 2019 \\ Address for correspondence \\ Sung Joon Park, MD \\ Department of Otorhinolaryngology- \\ Head and Neck Surgery, \\ Yeouido St. Mary's Hospital, \\ College of Medicine, \\ The Catholic University of Korea, \\ 10 63-ro, Yeongdeungpo-gu, \\ Seoul 07345, Korea \\ Tel +82-2-3779-1611 \\ Fax +82-2-786-1149 \\ E-mail hypocratis@gmail.com \\ Young Hak Park, MD, PhD \\ Department of Otorhinolaryngology- \\ Head and Neck Surgery, \\ Yeouido St. Mary's Hospital, \\ College of Medicine, \\ The Catholic University of Korea \\ 10 63-ro, Yeongdeungpo-gu, \\ Seoul 07345 , Korea \\ Tel +82-2-3779-1054 \\ Fax +82-2-786-1149 \\ E-mail yhpark7@catholic.ac.kr
}

Background and Objectives Radiesse ${ }^{\circledR}$ is a widely used calcium hydroxyapatite (CaHA) injection material used for vocal fold injection. Recently, a new CaHA injection material (Facetem $^{B}$ ) which complements the structural disadvantages of Radiesse has been developed and released in the market. The aim of this study is to compare the efficacy and short-term voice outcome of these two CaHA materials.

Subjects and Method A retrospective analysis was performed for 70 patients with unilateral vocal fold paralysis who underwent vocal fold injection using CaHA materials. Acoustic voice analysis, maximal phonation time (MPT), voice handicap index (VHI), and Grade, Roughness, Breathiness, Asthenia, Strain (GRBAS) scale were evaluated between Radiesse and Facetem injection group.

Results Both groups showed a signifcant improvement of MPT, VHI, and G, B, A scale after injection. The Facetem group showed similar voice improvement as the Radiesse group, where pre- and postoperatively objective and subjective voice evaluation results were compared.

Conclusion Our study reveals that there is no significant difference in efficacy and nor any short-term vocal improvement between Radiesse and Facetem. Therefore, the use of Facetem as CaHA injection material could be considered as an alternative material for patients with unilateral vocal cord paralysis. Korean J Otorhinolaryngol-Head Neck Surg 2019;62(10):575-82

Key Words Calcium hydroxyapatite $\cdot$ Injection laryngoplasty $\cdot$ Vocal cord paralysis.

\section{서 론}

일측성 성대마비(unilateral vocal fold paralysis)는 성대
자체 혹은 움직임에 관여하는 신경의 병적 상태로 인해 성대 운동의 물리적 제한이 발생하는 질환이다.) 이로 인해 발성 장애, 호흡불편감, 삼킴곤란 등 다양한 증상이 발생하며 환

This is an Open Access article distributed under the terms of the Creative Commons Attribution Non-Commercial License (https://creativecommons.org/licenses/by-nc/4.0) which permits unrestricted non-commercial use, distribution, and reproduction in any medium, provided the original work is properly cited. 
자의 삶의 질에 직접적인 영향을 미친다. ${ }^{2}$ 일측성 성대마비 의 치료 방법은 비침습적인 음성치료와 침습적인 수술적 치 료로 크게 분류할 수 있다. 성대주입술은 침습적인 치료 방 법 중 하나로 주입성분과 관계없이 주사바늘을 통해서 성대 에 이물질을 주입하는 모든 행위를 통칭한다. 성대주입술은 내전형 갑상성형술을 포함한 후두골격수술 또는 후두신경 재건술과 같은 다른 침습적 수술치료 방법과 비교하여 상대 적으로 비침습적이고, 합병증이 적으며, 주입하고자 하는 물 질의 종류에 따라 입원이나 전신마취 없이 국소마취하에 외 래에서 시행 가능하다는 여러 장점을 가지고 있어서 일측성 성대마비 환자들의 치료에 자주 사용되고 있다. ${ }^{3-5)}$

1911년 Bruening ${ }^{6}$ 이 파라핀을 이용하여 일측성 성대마비 환자에게 성대주입술을 최초로 시행한 이후 치료 효과를 극 대화하면서, 안정성이 보장되고, 생체에 적합한 주입물질에 대한 연구는 현재까지도 꾸준히 진행되고 있다. ${ }^{6-8)}$ 이상적인 성대 주입물질은 성대의 생물리학적인 특성과 유사하여 성 대의 정상적인 진동을 저해해서는 안 되며, 주입위치에서 머 무르며 쉽게 주변 조직으로 이동하거나 흡수되어서는 안 되 며, 정확한 주입량과 주입위치를 조절할 수 있도록 쉽게 주사 할 수 있어야 하고, 생체 내에서 부적절한 면역반응을 유발 하지 않고, 잘못 주입된 경우 쉽게 제거할 수 있어야 한다.

현재까지 알려질 주입물질 중 파라핀은 일부 환자들에게 심각한 염증반응을 유발하는 것이 보고 되었으며, 젤라틴 제 제(Gelfoam, Upjohn, Kalamazoo, MI, USA)는 생체 친화 적이나 단기간에 흡수되는 단점이 확인되었다. ${ }^{9}$ 대안으로 등 장한 테플론(Teflon, Mentor, Indianapolis, IN, USA)은 영 구적이지만, 주입부위에 부적절한 염증반응을 유발하여 육 아종을 형성한다고 보고되어 있으며,10) 자가지방은 체내 흡수 율을 예측할 수 없어 정확한 주입량을 사전에 알 수 없다는 한계점이 문제로 제기되고 있다. ${ }^{11)}$

Calcium hydroxylapatite(CaHA)는 현재 널리 이용되는 반영구적 주입물질 중 하나로, Radiesse(BioForm, Franksville, WI, USA)라는 상품명으로 알려져 있다. ${ }^{12)}$ 이 제품은 25 45 $\mu \mathrm{m}$ 크기의 미세구슬 형태로 만들어진 CaHA가 수용 성 겔 운반체와 혼합되어 있어 주사기를 통해서 쉽게 주입이 가능하며, 과민 반응이나 감염의 우려가 없고, 현존하는 반 영구적 성대주입물질 중 유일하게 성대주입에 대한 $\mathrm{FDA}$ 허 가를 받았다. ${ }^{13}$

한편 국내에서 다양한 크기의 $\mathrm{CaHA}$ 입자들 간에 발생 가능한 응집 현상을 보완하기 위하여 $\mathrm{CaHA}$ 입자 크기를 평 균 $34 \mu \mathrm{m}$ 로 균일화시킨 Facetem(CGbio, Seongnam, Korea)이 안면윤곽성형술에서 Radiesse를 대체할 만한 새로운 $\mathrm{CaHA}$ 주입물질로 몇 년 전에 시판되었다. 그러나 아직까지
일측성 성대마비 환자들을 대상으로 Facetem의 효용성과 음 성학적 결과에 대한 연구는 보고되지 않은 상태이다. 따라서 본 연구에서는 기존에 사용되고 있는 $\mathrm{CaHA}$ 제제인 Radiesse 와 보완된 $\mathrm{CaHA}$ 주입물질인 Facetem의 효용성 및 단기 음 성학적 결과를 비교 분석하여 성대 주입물질로서 Facetem 의 유용성을 평가해 보고자 한다.

\section{대상 및 방법}

본 연구는 2008년 6월부터 2017년 7월까지, 본 기관에서 일측성 성대마비 진단하에 $\mathrm{CaHA}$ 주입물질인 Radiesse 혹 은 Facetem을 사용하여 성대주입술을 시행받은 70 명의 환 자들을 대상으로 시행한 후향적 연구이다. 본 연구는 연구가 시행된 기관의 연구윤리위원회의를 통한 심의 및 승인을 득 한 연구이다(IRB No. SC14DISI0076). 일측성 성대마비는 외 래 첫 내원 시 시행한 굴곡 후두내시경(EPM-3500; Pentax ${ }^{\circledR}$, Tokyo, Japan)을 통해 진단하였고, 해당 기간 동안 성대주입 술 이외의 후두골격수술 및 후두신경재건술을 시행 받은 환 자들 및 다른 주입물질을 성대주입술에 사용한 환자들은 본 연구에서 제외하였다. 연구에 포함된 모든 환자들은 성대주입 술을 받는 것에 동의한 일측성 성대마비 환자들로 모든 성대 주입술은 외래에서, 국소마취하에, 굴곡 후두내시경으로 병변 을 관찰하면서, 26게이지 바늘로 경피적 경윤상갑상연골막 접근법으로 시행되었으며 $\mathrm{CaHA}$ 주입물질인 Radiesse 또는 Facetem을 병변 성대에 주입하였다.

성대 주입물질별 효용성을 평가하기 위해 모든 환자들에 서 시술 전과 시술 후 6 8주 사이에 음향분석 및 공기역학 적 검사를 활용한 객관적인 음성평가와 숙련된 음성언어치 료사가 시행한 청지각 검사 및 설문지를 활용한 환자의 주관 적인 음성평가를 모두 시행하였다.

음향분석을 위해 환자는 $5 \mathrm{~cm}$ 앞에 있는 마이크에 대고, 편안한 목소리로 3 초간 '아' 발성을 유지하였고, 이와 같은 방 식으로 검사를 4 5회 반복하였다. Computerized Speech Lab(model 4150, KayPENTAX, Lincoln Park, NJ, USA) 을 이용하여 환자의 음성을 저장 후, 채취한 음성 샘플 중 가 장 안정적인 발성을 선택해 분석을 시행하였다. 객관적인 음향 분석은 Multi-Dimensional Voice Program(model 4150B, KayPENTAX)을 활용하여 이루어졌으며 분석에는 기본주파 수(F0), 주파수변화율(jitter), 진폭변화율(shimmer), 소음대배 음비(noise harmonic ratio, NHR)를 비교 변수로 측정하였다. 공기역학적 검사는 Phonatory Aerodynamic System(PAS; model 6600, KayPENTAX)을 사용하여 편안한 목소리로 '아' 소리를 발성 하도록 하여 최장발성지속시간(maximum 
Injection Laryngoplasty Using Facetem I Lee HH, et al.

Table 1. Clinical characteristics of patients included in the study

\begin{tabular}{lcccc}
\hline & Radiesse $(\mathrm{n}=46)$ & Facetem $(\mathrm{n}=24)$ & $\mathrm{p}$-value & Total $(\mathrm{n}=70)$ \\
\hline Gender (male:female) & $22: 24$ & $18: 6$ & $0.029^{*}$ & $40: 30$ \\
Age & $56.52 \pm 16.39$ & $60.38 \pm 18.28$ & $0.373^{\dagger}$ & $57.84 \pm 17.03$ \\
Paralysis side (right:left) & $12: 34$ & $8: 16$ & $0.524^{*}$ & $20: 50$ \\
Injection volume $(\mathrm{mL})$ & $0.67 \pm 0.27$ & $0.70 \pm 0.27$ & $0.702^{\dagger}$ & $0.68 \pm 0.27$ \\
Follow up voice lab interval (months) & $2.07 \pm 2.80$ & $1.54 \pm 2.11$ & $0.241^{\ddagger}$ & $1.89 \pm 2.58$ \\
Number of patients needing additional injection $(\%)$ & $17(37)$ & $5(20.8)$ & $0.168^{*}$ & $22(31.4)$ \\
\hline
\end{tabular}

*Pearson chi-square test, tindependent t-test, łMann-Whitney U-test

phonation time, MPT)을 측정하였다. 주관적인 음성 평가는 음성장애지수(voice handicap index, VHI)를 통해 환자들 이 느끼는 음성 불편감을 확인하였고, 청지각적인 평가를 위 해 숙련된 음성언어치료사가 GRBAS scale을 이용하여 음질 저하정도(grade, $\mathrm{G})$, 조조성(roughness, R), 기식성(breathiness, B), 무력성(asthenia, A), 긴장성(strain, S)을 측정하였다.

Radiesse와 비교하였을 때 Facetem의 비열등성을 평가하 기 위하여 먼저 각 주입물질군별로 소속된 환자들의 성별, 연령, 성대마비의 원인, 방향, 주입량, 음성평가 시행 간격, 그 리고 시술 전 음성평가 결과의 차이를 비교분석하였다. 추가 로 각 주입물질별 성대주입술의 효용성을 평가하기 위하여 시술 후 음성평가 결과의 호전 여부를 분석하였고, 시술 전 후 시행한 음성평가 결과의 차이값을 비교분석하였다.

모든 통계분석은 SPSS 프로그램(ver. 19.0 for Windows; IBM Corp., Armonk, NY, USA)를 이용하여 시행하였다. 두 군 간의 비교를 위해 비연속 변수는 Pearson's chi-square test를 시행하였으며, 연속변수들을 비교분석할 경우에는 Kolmogorov-Smirnov test를 시행하여 정규분포 여부를 확 인한 후 정규분포를 하는 연속변수는 independent t-test를 그리고 정규분포를 하지 않은 연속변수는 Mann Whitney Utest를 시행하여 두 군 간의 차이를 비교하였다. 아울러 한 군내에서 시술 전후의 객관적 및 주관적 음성결과를 비교히 기 위해 paired t-test를 시행하였으며, $p<0.05$ 인 경우를 통 계적으로 유의한 것으로 간주하였다.

\section{결 과}

총 70명의 환자들 중 Radiesse 주입군은 46명, Facetem 주입군은 24 명이었다. 환자 연령은 19 세부터 86 세까지 분포 하였으며, 평균 연령은 Radiesse 56.52세, Facetem 60.38세였 다. 성별은 Radiesse 주입군은 남자 22명, 여자 24명이었고, Facetem 주입군은 남자 18명, 여자 6명이었다. 성대마비 방 향은 Radiesse 주입군은 우측 12 명, 좌측 34 명이었으며, Facetem 주입군은 우측 8 명, 좌측 16 명이었다. 평균 주입량은
Table 2. Etiology of vocal cord paralysis in a cohort

\begin{tabular}{lrrrr}
\hline & $\begin{array}{c}\text { Radiesse } \\
(\mathrm{n}=46, \%)\end{array}$ & $\begin{array}{c}\text { Facetem } \\
(\mathrm{n}=24, \%)\end{array}$ & $\begin{array}{c}\text { Total } \\
(\mathrm{n}=70, \%)\end{array}$ & p-value* \\
\hline Idiopathic & $9(19.6)$ & $5(20.8)$ & $14(20.0)$ & 0.099 \\
Post-thyroidectomy & $17(37.0)$ & $4(16.7)$ & $21(30.0)$ & \\
$\begin{array}{l}\text { Intrathoracic } \\
\quad \text { surgery }\end{array}$ & $6(13.0)$ & $4(16.7)$ & $10(14.3)$ & \\
$\begin{array}{l}\text { Neck dissection } \\
\text { Tumor invasion }\end{array}$ & $5(10.9)$ & $1(4.2)$ & $6(8.6)$ & \\
$\begin{array}{l}\text { Central nerve } \\
\text { system }\end{array}$ & $2(4.3)$ & $5(20.8)$ & $7(10.0)$ & \\
Post-traumatic & $6(13.2)$ & $3(12.5)$ & $4(5.7)$ & \\
\hline
\end{tabular}

*Pearson chi-square test

Radiesse $0.67 \mathrm{cc}$, Facetem $0.70 \mathrm{cc}$ 이었다. 두 군 간의 연령, 성대마비 방향, 주입량, 음성검사 시행 간격은 통계적으로 유 의한 차이를 보이지 않았다. 다만, 성별 구성의 경우 두 군 사 이에 통계적으로 유의한 차이를 보였다 $(p=0.029)$. 첫 주입술 이후 1년 이내에 성대주입술을 재시행받은 빈도를 비교한 결과 Radiesse 주입군은 전체 46명 중 17명(37\%), Facetem 주입군 은 전체 24 명 중 5 명(20.8\%)이 재시행을 받았다. 재시행 비율 은 두 군 사이에 통계적으로 유의한 차이를 보이지 않았다 $(p=0.168)$ (Table 1).

일측성 성대마비의 원인은 두 군에서 통계적으로 유의한 차이를 보이지는 않았으나 Radiesse의 경우 thyroidectomy 또는 neck dissection 후 발생한 일측성 성대마비 환자들에서 더 많이 사용하였고, Facetem의 경우 tumor invasion과 central nerve system 원인으로 발생한 일측성 성대마비 환자들 에서 더 많이 사용한 경향성을 보였다(Table 2).

시술 전 시행한 객관적인 음향 분석 및 공기역학적 검사에 서 F0, jitter, shimmer, NHR, MPT 값은 두 군 간에 유의한 차이는 없었다. 그러나 시술 전 평가자가 시행한 주관적 청지 각평가인 GRBAS scale의 경우 총점의 차이는 두 군 간에 없 었으나 각 항목별로 비교하였을 경우 Facetem군에서 조조 성 $(\mathrm{R})$ 은 낮은 환자들이 더 많았고 $(p=0.017)$, 긴장성(S)은 높 은 환자들이 더 많았다 $(p<0.001)$. 추가로 환자가 시행한 주 
관적 음성평가인 음성장애지수(VHI)는 Facetem군에서 시술 전에 통계적으로 유의하게 더 좋은 결과를 보였다 $(p=0.039)$ (Table 3).

시술 전후 시행한 객관적 및 주관적 음성평가 결과를 각 주입물질군 내에서 비교평가한 결과, Radiesse 주입군의 경 우 시술 후 소음대배음비(NHR)가 통계적으로 유의하게 감 소하였으며 $(p=0.034)$, 공기역학검사에서 최장발성지속시간 (MPT)이 통계적으로 유의하게 증가하였다 $(p<0.001)$. 주관 적 음성평가에서는 음성장애지수(VHI)가 시술 후 통계적으 로 유의하게 감소하였다 $(p<0.001)$ (Fig. 1).

Facetem 주입군의 경우 공기역학검사에서 Radiesse 주입 군과 유사하게 시술 후 최장발성지속시간(MPT)이 통계적으 로 유의하게 증가하였고 $(p=0.038)$, 주관적 음성 평가에서는
음성장애지수(VHI)가 시술 후 통계적으로 유의하게 감소하 였다( $p=0.035$ )(Fig. 2).

시술 전후 시행한 청지각적 평가 결과를 각 주입물질군 내 에서 비교한 결과, Radiesse 주입군의 경우 음질의 비정상정 도 $(\mathrm{G})$, 기식성 $(\mathrm{B})$, 무력성(A)에서 통계적으로 유의하게 시술 후 호전된 음성결과를 보였다 $(p<0.001)$. Facetem 주입군의 경우 음질의 비정상정도 $(\mathrm{G})$, 기식성 $(\mathrm{B})$, 무력성 $(\mathrm{A})$, 긴장성 $(\mathrm{S})$ 에서 통계적으로 유의하게 시술 후 호전된 음성결과를 보였 다(Fig. 3).

시술 전후 음성평가 항목별 차이값을 두 군 간에 비교분 석한 결과, 객관적 음향 분석 및 공기역학적 검사, 주관적 음 성장애지수, 그리고 청지각적 평가 중 조조성 $(\mathrm{R})$ 을 제외한 모든 항목에서 통계적으로 유의한 차이가 없는 것으로 확인

Table 3. Pre-injection voice evaluation results

\begin{tabular}{|c|c|c|c|c|c|}
\hline & & Radiesse $(n=46)$ & Facetem $(n=24)$ & $p$-value & Total \\
\hline \multicolumn{6}{|c|}{ Objective } \\
\hline \multicolumn{2}{|c|}{$\mathrm{FO}(\mathrm{Hz}, \mathrm{n}=64)$} & $178.33 \pm 57.20$ & $163.31 \pm 68.44$ & $0.364^{*}$ & $173.64 \pm 60.79$ \\
\hline \multicolumn{2}{|c|}{ Male $(n=35 / 40)$} & $155.05 \pm 44.08(n=20)$ & $136.20 \pm 37.93(n=15)$ & $0.194^{*}$ & $146.97 \pm 42.05$ \\
\hline \multicolumn{2}{|c|}{ Female $(n=29 / 30)$} & $197.73 \pm 60.40(n=24)$ & $244.61 \pm 78.70(n=5)$ & $0.144^{*}$ & $205.82 \pm 64.85$ \\
\hline \multicolumn{2}{|c|}{ Shimmer $(\%, n=64)$} & $9.67 \pm 6.59$ & $11.84 \pm 8.88$ & $0.279 *$ & $10.35 \pm 7.38$ \\
\hline \multicolumn{2}{|c|}{ Jitter $(\%, n=64)$} & $9.01 \pm 26.19$ & $4.96 \pm 3.96$ & $0.942^{\dagger}$ & $7.75 \pm 21.82$ \\
\hline \multicolumn{2}{|c|}{$\operatorname{NHR}(n=64)$} & $0.25 \pm 0.22$ & $1.11 \pm 3.91$ & $0.524^{\dagger}$ & $0.52 \pm 2.19$ \\
\hline \multicolumn{2}{|c|}{ MPT (sec, n=70) } & $6.63 \pm 4.26$ & $5.09 \pm 6.08$ & $0.222^{*}$ & $6.10 \pm 4.97$ \\
\hline \multicolumn{6}{|c|}{ Subjective } \\
\hline \multicolumn{2}{|c|}{$\mathrm{VHI}(\mathrm{n}=70)$} & $65.04 \pm 30.91$ & $48.25 \pm 32.96$ & $0.039 *$ & $59.29 \pm 32.40$ \\
\hline \multirow[t]{4}{*}{$G(\%)$} & 0 & $0(0)$ & $0(0)$ & $0.136^{\ddagger}$ & 0 \\
\hline & 1 & $5(10.9)$ & $1(4.2)$ & & $6(8.6)$ \\
\hline & 2 & $14(30.4)$ & $13(54.2)$ & & $27(38.6)$ \\
\hline & 3 & $27(58.7)$ & $10(41.7)$ & & $37(52.9)$ \\
\hline \multirow[t]{4}{*}{$\mathrm{R}(\%)$} & 0 & $6(13.0)$ & $8(33.3)$ & $0.017^{\ddagger}$ & $14(20.0)$ \\
\hline & 1 & $18(39.1)$ & $13(54.2)$ & & $31(44.3)$ \\
\hline & 2 & $15(32.6)$ & $3(12.5)$ & & $18(25.7)$ \\
\hline & 3 & $7(15.2)$ & $0(0)$ & & $7(10.0)$ \\
\hline \multirow[t]{4}{*}{ B (\%) } & 0 & $3(6.5)$ & $1(4.2)$ & $0.202^{\ddagger}$ & $4(5.7)$ \\
\hline & 1 & $6(13.0)$ & $0(0)$ & & $6(8.6)$ \\
\hline & 2 & $18(39.1)$ & $14(58.3)$ & & $32(45.7)$ \\
\hline & 3 & 19 (41.3) & $9(37.5)$ & & $28(40.0)$ \\
\hline \multirow[t]{4}{*}{ A (\%) } & 0 & $16(34.8)$ & $6(25.0)$ & $0.273^{\ddagger}$ & $22(31.4)$ \\
\hline & 1 & $21(45.7)$ & $13(54.2)$ & & $34(48.6)$ \\
\hline & 2 & $5(10.9)$ & $5(20.8)$ & & $10(14.3)$ \\
\hline & 3 & $4(8.7)$ & $0(0)$ & & $4(5.7)$ \\
\hline \multirow[t]{4}{*}{ S (\%) } & 0 & $29(63.0)$ & $1(4.2)$ & $<0.001 \ddagger$ & $30(42.9)$ \\
\hline & 1 & $10(21.7)$ & $10(41.7)$ & & $20(28.6)$ \\
\hline & 2 & $5(10.9)$ & $8(33.3)$ & & $13(18.6)$ \\
\hline & 3 & $2(4.3)$ & $5(20.8)$ & & $7(10.0)$ \\
\hline \multicolumn{2}{|c|}{ Total GRBAS } & $7.63 \pm 2.39$ & $8.13 \pm 2.40$ & $0.415^{*}$ & $7.80 \pm 2.39$ \\
\hline
\end{tabular}

*independent t-test, †Mann Whitney U-test, łPearson chi-square test. FO: fundamental frequency, NHR: noise harmonic ratio, MPT: maximum phonation time, VHI: voice handicap index, G: grade, R: roughness, B: breathiness, A: asthenia, S: strain 


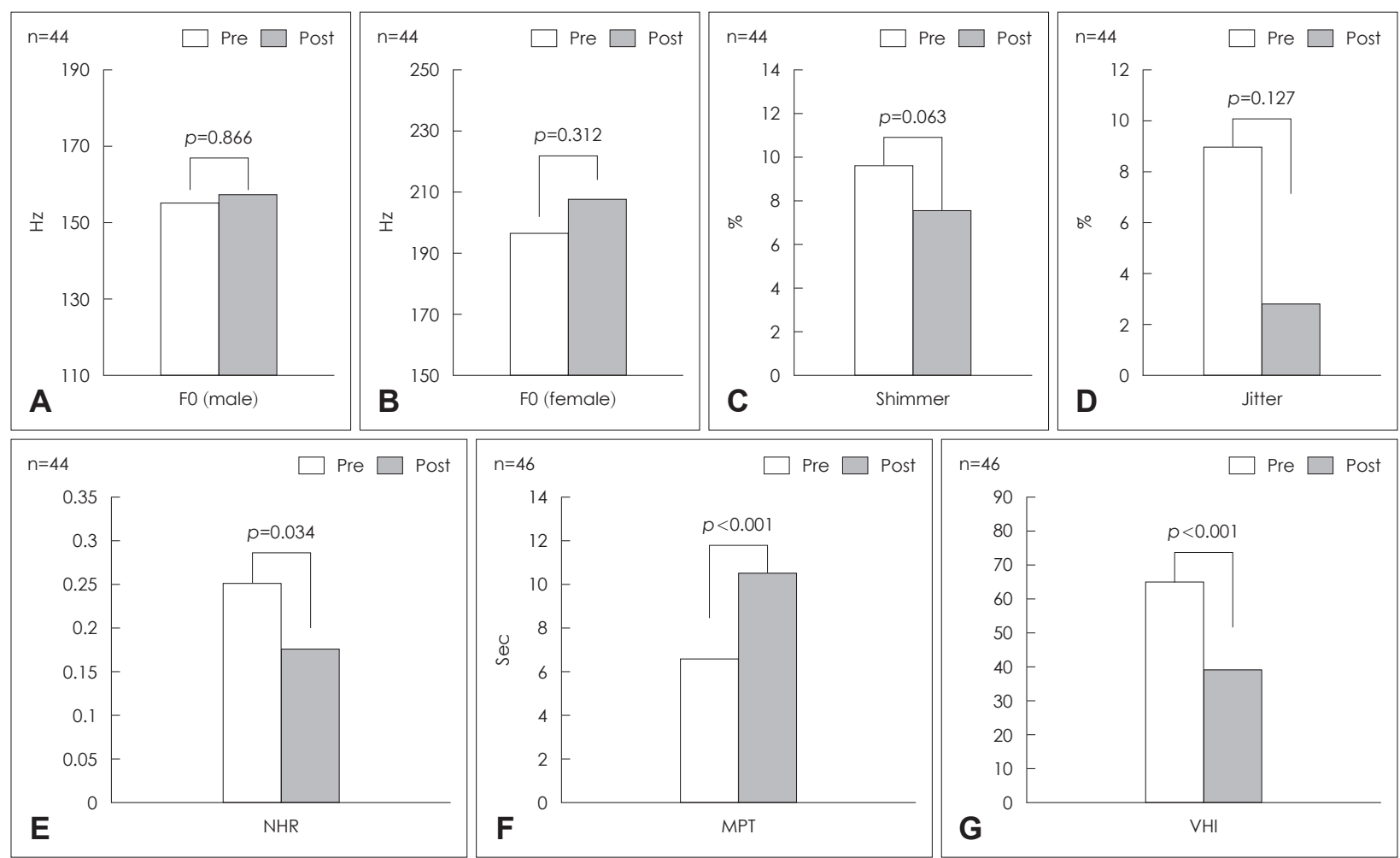

Fig. 1. Pre/post voice evaluation for Radiesse injection group. A total of 46 patients underwent Radiesse injection and two of them did not have follow up acoustic analysis (A-E). NHR, MPT, and VHI significantly changed after Radiesse injection (E-G). F0 of male (Hz) (A), F0 of female $(\mathrm{Hz})(\mathrm{B})$, shimmer (\%) (C), jitter (\%) (D), NHR (E), MPT (sec) (F), VHI (G). F0: fundamental frequency, NHR: noise harmonic ratio, MPT: maximum phonation time, $\mathrm{VHI}$ : voice handicap index.

되었다(Table 4).

\section{고 찰}

성대주입술은 일측성 성대마비의 대표적인 치료로서 상대 적으로 비침습적이고, 합병증이 적으며 가장 긴 역사를 갖고 있는 치료 방법이다. ${ }^{14)}$ 성대주입술의 일차적 목표는 주입물질 을 통해 병변부 성대를 내전시켜 환자의 음성을 회복하고, 삶의 질을 향상시키는 것이다. ${ }^{15}$ 환자의 객관적인 음성 수치 와 주관적인 만족도를 모두 고려하는 것이 성대 주입물질의 효과를 판정하는데 중요한 요소로 작용한다. 본 연구를 통해 Radiesse와 Facetem 모두 성대주입술에 효과적인 $\mathrm{CaHA}$ 제제임을 확인하였으며, 거의 동등한 수준의 단기 음성효과 를 가지는 것으로 확인되었다.

기존의 연구에 따르면 $\mathrm{CaHA}$ 주입술은 자가지방주입술과 음성효과에서 큰 차이를 보이지 않았으며, ${ }^{16)} \mathrm{CaHA}$ 주입술 과 내전갑상성형술을 비교한 단기 연구에서도 대등한 음성효 과를 보였다. ${ }^{17)}$ 하지만 아직까지 $\mathrm{CaHA}$ 제제들 간의 음성효 과를 비교한 연구는 보고되지 않은 상태이다. 따라서 본 연 구는 이전까지 없었던 두 가지 $\mathrm{CaHA}$ 제제들 간의 비교 연 구라는 점에서 기존의 연구들과는 다른 의의를 갖는다.
일측성 성대마비를 유발하는 원인은 기관 내 삽관술, ${ }^{18)}$ 미 주신경 혹은 되돌이후두신경을 침범하는 종양 ${ }^{19}$ 뿐만 아니 라 갑상선절제술, 흥부수술과 같은 의인성 원인 ${ }^{20)}$ 그리고 원 인미상의 성대마비 ${ }^{21)}$ 등과 같이 다양하다. 본 연구에서는 일 측성 성대마비 환자에게 Radiesse 및 Facetem을 주입한 결 과를 비교분석하였으며, 두 주입군 간 적응증의 차이를 두진 않았다. 다만 본 기관에 Facetem이 소개되기 전까지는 주로 Radiesse가 성대주입술에 사용되었으며 Facetem이 소개된 이후에는 주로 Facetem이 성대주입술에 사용되었다. 주입물 질 사용에 이러한 시기적인 차이때문인지는 명확하지 않으나 Radiesse 주입군에 갑상선수술 후 또는 경부수술 후 발생한 일측성 성대마비 환자들이 상대적으로 많이 포함되었고 $\mathrm{Fac}^{-}$ etem 주입군에 암의 신경 침범이나 중추신경 문제로 인한 일 측성 성대마비 환자들이 상대적으로 많이 포함되어 있었으나 결과적으로 두 군 간 성대마비의 원인에 통계적으로 유의한 차이를 보이진 않았으며, 다양한 원인에 의한 성대마비 환자 들에서 두 주입물질이 음성적 향상을 가져온다는 사실을 확 인할 수 있었다.

Radiesse는 다양한 크기의 CaHA 입자가 수용성 겔인 carboxyl methyl cellulose에 현탁된 주사제이다. 성대에 주입된 이후 수용성 겔은 체내에 흡수되고, $\mathrm{CaHA}$ 입자만 남아 성 
대 부피를 유지하는 역할을 하게 된다. ${ }^{22,23)}$ 하지만 유체 내의 $\mathrm{CaHA}$ 입자들의 크기 분포가 다양할수록 응집 침강 현상이 활발하게 작용하여, ${ }^{24)}$ 기존의 부피와 모양을 유지하지 못한 채 응집될 가능성이 높아진다. ${ }^{25,26)}$ 실제로 Radiesse 주입 후 성대 경직, 용적 감소 그리고 주입 부위 이탈과 같은 사례가
여러 연구에서 보고된 바 있다. ${ }^{3,27-29)}$

입자 간의 크기가 균일할수록, 용해 평형에 도달하여 용해 와 응집이 같은 정도로 유지되지만, 입자 간 크기가 서로 다 른 경우, 큰 입자를 중심으로 응집 현상이 더 활발하게 작용 한다. 따라서 균일한 입자의 크기는 구조적 안정성을 유지하

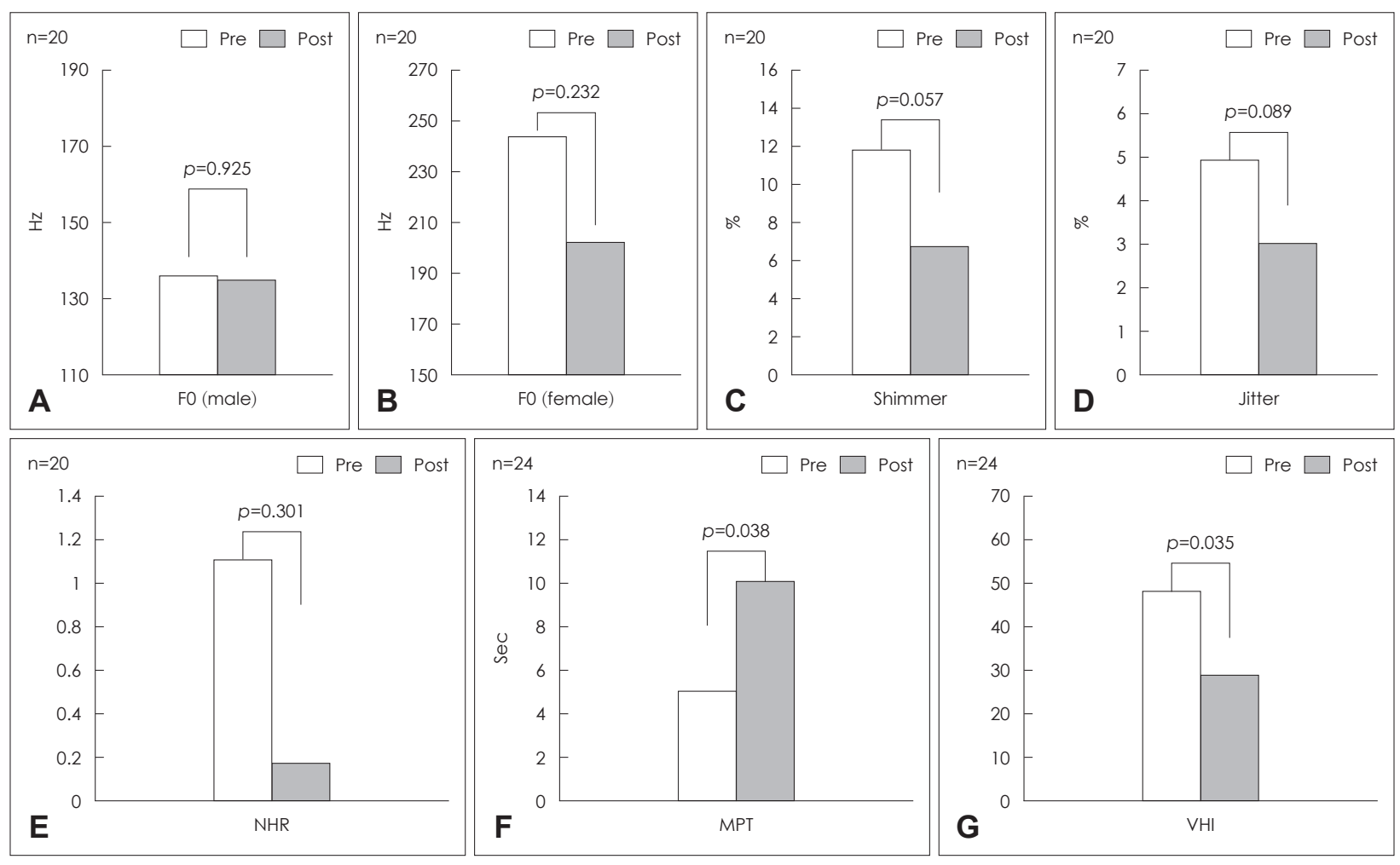

Fig. 2. Pre/post voice evaluation for Facetem injection group. A total of 24 patients underwent Facetem injection and four of them did not have follow up acoustic analysis (A-E). MPT and VHI significantly changed after Facetem injection (F and G). F0 of male (Hz) (A), F0 of female $(\mathrm{Hz})(\mathrm{B})$, shimmer (\%) (C), jitter (\%) (D), NHR (E), MPT (sec) (F), VHI (G). NHR: noise harmonic ratio, MPT: maximum phonation time, VHI: voice handicap index, FO: fundamental frequency.

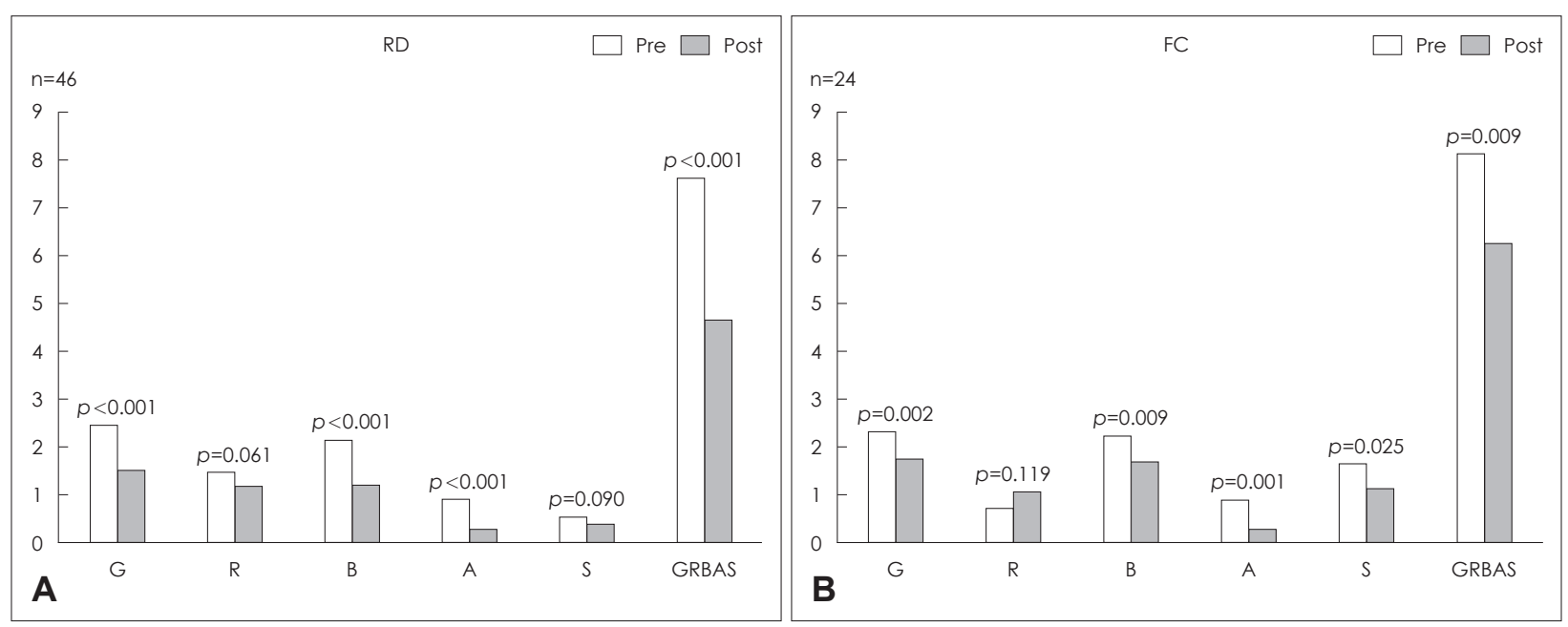

Fig. 3. Pre/post GRBAS scale evaluation for Radiesse and Facetem injection group. A total of 46 patients underwent Radiesse injection and G, B, A scale significantly changed after injection (A). A total of 24 patients underwent Facetem injection and G, B, A, S scale significantly changed after injection (B). G: grade, R: roughness, B: breathiness, A: asthenia, S: strain, RD: Radiesse injection group, FC: Facetem injectin gruop. 
Injection Laryngoplasty Using Facetem I Lee HH, et al.

Table 4. Difference of pre- and post-injection voice evaluation results

\begin{tabular}{lllll}
\hline & Radiesse $(n=46)$ & Facetem $(n=24)$ & p-value & Total \\
\hline Objective & & & & \\
Post FO-pre FO $(\mathrm{Hz}, \mathrm{n}=64,44: 20)$ & $7.06 \pm 56.20$ & $-11.07 \pm 43.94$ & $0.207^{*}$ & $1.40 \pm 53.01$ \\
$\quad$ Male $(\mathrm{n}=35 / 40)$ & $2.37 \pm 61.93(\mathrm{n}=20)$ & $-0.74 \pm 29.81(\mathrm{n}=15)$ & $0.846^{*}$ & $1.03 \pm 50.12$ \\
$\quad$ Female $(\mathrm{n}=29 / 30)$ & $10.98 \pm 51.98(\mathrm{n}=24)$ & $-42.07 \pm 66.78(\mathrm{n}=5)$ & $0.058^{*}$ & $-1.83 \pm 57.21$ \\
Post shimmer-pre shimmer $(\mathrm{n}=64,44: 20)$ & $-2.10 \pm 7.31$ & $-5.13 \pm 11.32$ & $0.284^{*}$ & $-3.05 \pm 8.78$ \\
Post jitter-pre jitter & $-6.18 \pm 26.33$ & $-1.91 \pm 4.76$ & $0.942^{\dagger}$ & $-4.85 \pm 22.00$ \\
Post NHR-pre NHR & $-0.08 \pm 0.23$ & $-0.93 \pm 3.91$ & $0.638^{\dagger}$ & $-0.34 \pm 2.19$ \\
Post MPT-pre MPT ${ }^{\ddagger}$ & $3.92 \pm 5.23$ & $5.02 \pm 11.17$ & $0.576^{*}$ & $4.30 \pm 7.73$ \\
Subjective & & & & \\
Post VHI-pre VHI $(\mathrm{n}=70,46: 24)$ & $-25.76 \pm 35.78$ & $-19.00 \pm 41.46$ & $0.480^{*}$ & $-23.44 \pm 37.66$ \\
Post G-pre G & $-0.93 \pm 0.85$ & $-0.54 \pm 0.78$ & $0.100^{\dagger}$ & $-0.80 \pm 0.84$ \\
Post R-pre R & $-0.30 \pm 1.07$ & $0.33 \pm 1.01$ & $0.031^{\dagger}$ & $-0.09 \pm 1.09$ \\
Post B-pre B & $-0.93 \pm 1.04$ & $-0.54 \pm 0.93$ & $0.168^{\dagger}$ & $-0.80 \pm 1.02$ \\
Post A-pre A & $-0.63 \pm 1.02$ & $-0.58 \pm 0.72$ & $0.837^{\dagger}$ & $-0.61 \pm 0.92$ \\
Post S-pre S & $-0.15 \pm 0.60$ & $-0.50 \pm 1.02$ & $0.065^{\dagger}$ & $-0.27 \pm 0.78$ \\
Post GRBAS-pre GRBAS & $-2.96 \pm 2.76$ & $-1.83 \pm 3.14$ & $0.128^{*}$ & $-2.57 \pm 2.93$ \\
\hline
\end{tabular}

*independent t-test, tMann Whitney U-test, $\neq(n=70,46: 24)$. NHR: noise harmonic ratio, MPT: maximum phonation time, VHI: voice handicap index, G: grade, R: roughness, B: breathiness, A: asthenia, S: strain, F0: fundamental frequency

는데 중요한 요소로 작용한다. ${ }^{24,25)}$ 최근 국내에서 시판된 Facetem은 Radiesse와 동일한 성분이면서, $\mathrm{CaHA}$ 입자의 크기를 보다 균일화하여 입자의 응집 현상을 줄여주고, 물리 적으로 더 안정된 구조를 갖고 있다. 본 연구에서는 첫 주입 술 이후 1 년 이내 재시행 비율이 두 주입물질 사이에 유의한 차이를 보이지는 않았지만 각 주입물질군의 구성에 다소 차 이를 보이는 한계점이 있었다. 따라서 Radiesse와 비교하여 Facetem의 장기적인 효용성을 입증하기 위해서는 성별, 나이, 성대마비의 원인, 그리고 시술 전 객관적 및 주관적 음성결 과를 매칭하여 Radiesse와 Facetem의 주입물질 이탈 정도 및 용적 감소률을 비교하는 전향적 연구가 필요할 것으로 생 각된다.

본 연구에서는 시술 전후 시행한 청지각적 평가 항목 중 조조성 $(\mathrm{R})$ 척도에서 두 군 간에 유의한 차이를 보였다. 그러 나 성문폐쇄부전 시 가장 현저하게 영향받는 기식성(B) 척도 를 포함한 나머지 모든 항목에서 통계적으로 유의한 차이가 없었다. ${ }^{30)}$ 추가로 성문폐쇄부전의 공기역학적 발성 효율을 가 장 신뢰성 있게 평가할 수 있는 최장발성지속시간(MPT)에 서도 시술 전후 두 군 간의 유의한 차이가 없는 것으로 확인 되었다. ${ }^{31)}$ 이를 근거로 일측성 성대마비 환자에서 Facetem 성대주입술의 유용성을 확인하였고, 단기 음성학적 결과에 서 Radiesse와 Facetem 두 집단 간의 유의한 차이가 없는 것으로 확인되었다.

본 연구에서는 후향적 연구라는 제한점 때문에 시술 전 마 비측 성대가 고정된 위치와 성대점막 진동의 대칭성을 볼 수
있는 스트로보스코프 결과가 분석 변수에 포함되지 못했다. 따라서 이와 같은 정보들이 영향을 줄 수 있는 청지각적 평 가의 조조성 $(\mathrm{R})$ 과 긴장성 $(\mathrm{S})$ 척도 및 음성장애지수가 시술 전에 두 군에서 유의한 차이를 보인 부분을 설명하는 데에 한 계점를 가지고 있다.

본 연구의 또 다른 제한점은 Radiesse와 Facetem 두 집단 간 성별 구성 비율에 유의한 차이를 보였다는 점이다. 아울 러 본 연구에 포함된 일측성 성대마비 환자들에서 그 원인이 매우 다양하게 분포되어 각 원인별로 균일하지 못한 음성평 가 결과를 보일 수 있으며, 두 주입물질군에서 시술 전 VHI 와 R 그리고 S score의 차이가 있었던 것을 고려해 보았을 때 비교하고자 하는 두 연구 집단이 아주 동일한 집단이었다고 단정할 수 없다는 제한점을 가지고 있다. 또한 음성학적 추적 관찰 기간이 평균 2개월 이내로 짧아 Facetem이 반영구적 주입물로서 Radiesse와 동등한 역할을 할 수 있을지에 대해 서는 명확하게 파악할 수 없다는 제한점이 있다.

따라서 성별, 나이, 일측성대마비의 원인, 그리고 시술 전 객관적 및 주관적 음성결과를 매칭하여 더 많은 숫자의 환 자들을 대상으로 1 년 이상 장기간에 걸친 추적 관찰을 하는 전향적 연구를 통해 $\mathrm{CaHA}$ 제재의 성대 주입물질로서 $\mathrm{Fac}^{-}$ etem의 장기적인 유용성 및 안정성을 평가하는 추가 연구가 필요할 것으로 생각된다.

본 임상 연구를 통해 CaHA 제제인 Radiesse와 Facetem 은 효용성 및 단기간의 음성 향상 정도에 유의한 차이를 보 이지 않는 것으로 확인되었다. 따라서 일측성 성대마비의 환 
자를 위한 성대주입술 시, $\mathrm{CaHA}$ 제제 선택에 있어 Facetem 을 또 다른 옵션으로 고려해 볼 수 있을 것이다. 앞으로 Facetem에 대한 장기적인 유용성과 음성 효과를 파악하기 위해 서는 균일한 환자군에서 더 많은 환자들을 대상으로 장기적 인 추척 관찰이 동반되는 연구가 이루어져야 할 것이다.

\section{ORCID}

Sung Joon Park https://orcid.org/0000-0001-6370-5997

\section{REFERENCES}

1) Prasad VMN, Fakhoury R, Helou D, Lawson G, Remacle M. Unilateral vocal fold immobility: A tertiary hospital's experience over 5 years. Eur Arch Otorhinolaryngol 2017;274(7):2855-9.

2) Mortensen M, Carroll L, Woo P. Arytenoid adduction with medialization laryngoplasty versus injection or medialization laryngoplasty: The role of the arytenoidopexy. Laryngoscope 2009;119(4):827-31.

3) Rosen CA, Thekdi AA. Vocal fold augmentation with injectable calcium hydroxylapatite: Short-term results. J Voice 2004;18(3): 387-91.

4) Isshiki $\mathrm{N}$, Morita $\mathrm{H}$, Okamura $\mathrm{H}$, Hiramoto $\mathrm{M}$. Thyroplasty as a new phonosurgical technique. Acta Otolaryngol 1974;78(5-6):451-7.

5) Paniello RC. Laryngeal reinnervation. Otolaryngol Clin North Am 2004;37(1):161-81.

6) Bruening W. Über eine neue behandlungsmethode der rekurrenslahmung. Verhandl Deutsch Laryngol 1911;18:93.

7) King JM, Simpson CB. Modern injection augmentation for glottic insufficiency. Curr Opin Otolaryngol Head Neck Surg 2007;15(3): 153-8.

8) Nakayama M, Ford CN, Bless DM. Teflon vocal fold augmentation: Failures and management in 28 cases. Otolaryngol Head Neck Surg 1993;109(3 Pt 1):493-8.

9) Schramm VL, May M, Lavorato AS. Gelfoam paste injection for vocal cord paralysis: Temporary rehabilitation of glottic incompetence. Laryngoscope 1978;88(8 Pt 1):1268-73.

10) Dedo HH. Injection and removal of Teflon for unilateral vocal cord paralysis. Ann Otol Rhinol Laryngol 1992;101(1):81-6.

11) Mikaelian DO, Lowry LD, Sataloff RT. Lipoinjection for unilateral vocal cord paralysis. Laryngoscope 1991;101(5):465-8.

12) Hughes RG, Morrison M. Vocal cord medialization by transcutaneous injection of calcium hydroxylapatite. J Voice 2005;19(4):674-8.

13) Belafsky PC, Postma GN. Vocal fold augmentation with calcium hydroxylapatite. Otolaryngol Head Neck Surg 2004;131(4):351-4.

14) Benninger MS, Hanick AL, Nowacki AS. Augmentation autologous adipose injections in the larynx. Ann Otol Rhinol Laryngol 2016; 125(1):25-30.

15) Rosen CA, Simpson CB. Operative techniques in laryngology. 1st ed. New York, NY: Springer;2008. p.91-6.
16) Zeleník K, Walderová R, Kučová $H$, Jančatová D, Komínek P. Comparison of long-term voice outcomes after vocal fold augmentation using autologous fat injection by direct microlaryngoscopy versus office-based calcium hydroxylapatite injection. Eur Arch Otorhinolaryngol 2017;274(8):3147-51.

17) Shen T, Damrose EJ, Morzaria S. A meta-analysis of voice outcome comparing calcium hydroxylapatite injection laryngoplasty to silicone thyroplasty. Otolaryngol Head Neck Surg 2013;148(2):197208.

18) Parnell FW, Brandenburg JH. Vocal cord paralysis. A review of 100 cases. Laryngoscope 1970;80(7):1036-45.

19) Maisel RH, Ogura JH. Evaluation and treatment of vocal cord paralysis. Laryngoscope 1974;84(2):302-16.

20) Terris DJ, Arnstein DP, Nguyen HH. Contemporary evaluation of unilateral vocal cord paralysis. Otolaryngol Head Neck Surg 1992; 107(1):84-90.

21) Titche LL. Causes of recurrent laryngeal nerve paralysis. Arch Otolaryngol 1976;102(5):259-61.

22) Mallur PS, Morrison MP, Postma GN, Amin MR, Rosen CA. Safety and efficacy of carboxymethylcellulose in the treatment of glottic insufficiency. Laryngoscope 2012;122(2):322-6.

23) Kwon TK, Rosen CA, Gartner-Schmidt J. Preliminary results of a new temporary vocal fold injection material. J Voice 2005;19(4): 668-73.

24) Nutan MTH, Reddy IK. General principles of suspensions. In: Kulshreshtha AK, Singh ON, Wall GM, editors. Pharmaceutical Suspensions: From Formulation Development to Manufacturing. 1st ed. New York, NY: Springer;2009. p.39-63.

25) Lee MH, Koo YS. New pharmacy. 3rd ed. Seoul: Ewha Womans University Press;2004. p.335-44.

26) Tadros TF. Correlation of viscoelastic properties of stable and flocculated suspensions with their interparticle interactions. Adv Colloid Interface Sci 1996;68(15):97-200.

27) Buchanan AG, Holds JB, Vagefi MR, Bidar M, McCann JD, Anderson RL. Anterior filler displacement following injection of calcium hydroxylapatite gel (Radiesse) for anophthalmic orbital volume augmentation. Ophthalmic Plast Reconstr Surg 2012; 28(5):335-7.

28) DeFatta RA, Chowdhury FR, Sataloff RT. Complications of injection laryngoplasty using calcium hydroxylapatite. J Voice 2012;26(5):614-8.

29) Ting JY, Patel R, Halum SL. Managing voice impairment after injection laryngoplasty. J Voice 2012;26(6):797-800.

30) Kim GW, Park YH, Joo YH, Kim SY, Shim MR, Hwang YS, et al. Benefits of palliative office-based hyaluronic acid injection laryngoplasty in cancer-related unilateral vocal cord paralysis patients. J Korean Soc Laryngol Phoniatr Logop 2018;29(1):30-6.

31) Woo JH, Baek MK, Kim DY, Park HM, An S, Moon KH, et al. Injection karyngoplasty for the treatment of vocal fold scar, and sulcus. J Korean Soc Laryngol Phoniatr Logop 2016;27(1):25-9. 